\title{
Meta-analysis of laboratory results in patients with severe coronavirus disease 2019
}

\author{
YUN HUANG, YUYU ZHANG and LILI MA \\ Department of Pharmacy, Ningbo Medical Center, Li Huili Hospital, Ningbo, Zhejiang 315040, P.R. China
}

Received May 22, 2020; Accepted January 13, 2021

DOI: $10.3892 /$ etm.2021.9877

\begin{abstract}
The aim of the present study was to analyze the differences in laboratory results between patients with severe and moderate coronavirus disease 2019 (COVID-19) for clinical intervention. The laboratory results of patients with COVID-19 between December 2019 and May 2020 were assembled from the Medline, Embase and Cochrane Library databases. A meta-analysis was conducted, calculating the individual and pooled odds ratios (ORs) with relative 95\% confidence intervals (95\% CIs) using Review Manager 5.3. The available data of 1,534 patients from 6 studies were included in this analysis. The results demonstrated that the incidence of leukocytosis, lymphocytopenia, increased procalcitonin (PCT), C-reactive protein (CRP), aspartate aminotransferase (AST) and lactic dehydrogenase (LDH) levels was associated with a nearly 3-fold $(\mathrm{OR}=3.44$; 95\% CI: 2.15-5.49), 4-fold ( $\mathrm{OR}=4.39 ; 95 \%$ CI: 1.82-10.60), 5-fold $(\mathrm{OR}=5.28 ; 95 \% \mathrm{CI}: 3.42-8.15)$, 4-fold $(\mathrm{OR}=3.99$; 95\% CI: 2.61-6.12), 3-fold (OR=3.02; 95\% CI: 2.13-4.26) and 8 -fold $(\mathrm{OR}=8.33$; 95\% CI: 1.75-39.69) higher risk of severe COVID-19 infection, respectively. These findings indicated that serial white blood cell count, lymphocyte count, CRP, PCT, LDH and AST measurements may be useful for predicting progression towards a more severe form of COVID-19.
\end{abstract}

\section{Introduction}

Coronavirus disease 2019 (COVID-19) is a novel type of respiratory pneumonia and persistent systemic illness caused by the severe acute respiratory syndrome coronavirus 2 (SARS-CoV-2). This disease has spread globally, and according to the COVID-19 Situation Report-73 from the World Health Organization, until April 2, 2020, there have been 896,450 confirmed cases and 45,542 deaths globally (1). The rapid

Correspondence to: Ms Lili Ma, Department of Pharmacy, Ningbo Medical Center, Li Huili Hospital, 57 Xingning Road, Ningbo, Zhejiang 315040, P.R. China

E-mail: mary258102@163.com

Key words: coronavirus disease 2019, laboratory results, meta-analysis measures taken by the Chinese government to control this outbreak have been highly successful.

Studies investigating the epidemiological and clinical characteristics indicate that the Chinese population are susceptible to COVID-19, as reported in The Diagnosis and Treatment of Coronavirus disease 2019 (Version 7) of National Health Commission of the P.R. China $(2,3)$. Its transmission route is through the respiratory system and close person-to-person contact, and it may involve aerosol dispersion; the incubation period is 1-14 days (3). Fever and cough are the most common symptoms, whereas hypertension and diabetes are the most prevalent comorbidities in patients with COVID-19 infection (4,5). A meta-analysis reported a fatality rate of $7 \%$ among COVID-19 patients, which is lower compared with that of the other two coronavirus species, namely the severe acute respiratory syndrome coronavirus (SARS-COV) and Middle East respiratory syndrome coronavirus (MERS-COV), which have fatality rates of $>10$ and $35 \%$, respectively (6). The high death rate is due to the high proportion of severe cases resulting in acute respiratory distress syndrome and multiorgan failure $(3,4)$.

Patients with severe COVID-19 have different clinical characteristics and case fatality rates compared with those with moderate infection. Laboratory medicine plays a key role in clinical decision making in several other infectious diseases. By contrast, there are no characteristic differences in laboratory abnormalities between patients with moderate and those with severe COVID-19. In the present study, laboratory results were assembled through a systematic search. Information on the incidence of increased or reduced white blood cell count, lymphocyte count, C-reactive protein (CRP), procalcitonin (PCT), lactic dehydrogenase (LDH) and aspartate aminotransferase (AST) levels was included. The differences were analyzed, and the data were examined to investigate whether the variations may play a role in distinguishing patients with severe or moderate COVID-19 disease for clinical intervention.

\section{Data and methods}

Literature search and selection. A systematic literature search was conducted on studies published in online databases, including PubMed, Embase and Cochrane Library, between December 2019 and May 2020. The keywords included 'Coronavirus Disease 2019' OR '2019-nCoV' OR 'COVID-19' AND 'clinical characteristics', without date or language 
restrictions. EndNote X6.0 software (Thomson Reuters Corporation) was used to manage the records and exclude duplicates. The reference lists were also checked for other potentially eligible studies to ensure the comprehensiveness of the research.

Severe disease was defined in this analysis following the national treatment guideline of COVID-19 (in Chinese) or according to the patient's need for admission to the intensive care unit (ICU) (7). Thus, patients in different studies were divided into severe and non-severe groups, or ICU and non-ICU groups. The inclusion criteria were as follows: i) Study population: Patients with diagnosed COVID-19. ii) Study design: Case studies involving infected individuals with severe and moderately severe symptoms. iii) Outcome measures: At least one reported change in laboratory indicators among leukocytosis, leukocytopenia, CRP, PCT, AST and LDH. The exclusion criteria were as follows: i) Abstracts from conferences and commentary articles; and ii) case reports, family-based studies and solely pediatric cases.

Data extraction and quality assessment. Evaluation of data extraction and quality of the literature was conducted independently by two researchers (HY and YYZ). Disagreements were resolved by consulting with a third investigator (LLM) or by reaching consensus.

Although the Newcastle-Ottawa Scale (NOS) is the most frequently reported tool for non-randomized studies (8), the methodological index for non-randomized studies (MINORS) was selected to evaluate the risk of bias in the present analysis (9). As it was difficult to evaluate the exposure factors in the studies included in this analysis, except for the items related to exposure factors, the remaining NOS items were similar to the MINORS items. The ideal global score of MINORS would be 16 for non-comparative studies. Article quality was assessed as follows: Low quality $=0-8$; moderate quality $=9-12$; and high quality=13-16.

Statistical analysis. Studies were divided into two separate groups for analysis, namely severe and moderate groups. The meta-analysis was conducted by calculating the individual and pooled odds ratios (ORs) with their relative $95 \%$ confidence intervals (95\% CIs) by Review Manager 5.3 (Copenhagen: The Nordic Cochrane Centre, The Cochrane Collaboration, 2014). Heterogeneity among studies was tested using Cochran's $\chi^{2}$ test and $\mathrm{I}^{2}$; when $\mathrm{I}^{2}<50 \%$, a fixed-effects model was used; by contrast, when $\mathrm{I}^{2}>50 \%$, a random-effects model was selected. Since approaches to detecting publication bias would have exhibited limited efficacy, publication bias was not assessed in the present report, as only a limited number of studies were included.

\section{Results}

Study selection. A total of 184 articles were compiled from the online databases. Following the deletion of duplicate records, 143 records were retained. The titles and abstracts were checked and the full texts were reviewed. A total of 6 studies (10-15) eventually met the eligibility criteria and were processed for inclusion in the final meta-analysis. Although there were no ethnic restrictions, the relevant studies retrieved during the literature search between December 2019 and May 2020 were all published in China; thus, all the studies covered in our analysis are in Chinese. An outline of the literature search process is shown in Fig. 1.

All the selected articles were assessed for methodological quality. The quality score of each study is presented in Table I. Of the 6 studies, 3 were of high quality and 3 were of moderate quality. The characteristics of the included studies are summarized in Table II.

Incidence of leukocytosis, lymphocytopenia, increased PCT and CRP levels. Through meta-analysis, it was established that, among all the laboratory indicators in patients with severe COVID-19, when compared with infected patients with moderate disease, the presence of leukocytosis was associated with a $\sim 3$-fold higher risk (OR=3.44; 95\% CI: 2.15-5.49, $\mathrm{I}^{2}=0 \%$; Fig. 2); the presence of lymphocytopenia was associated with a $\sim 4$-fold higher risk (OR=4.39; 95\% CI: 1.82-10.60, $\mathrm{I}^{2}=51 \%$; Fig. 3); increased PCT was associated with an $\sim 5$-fold higher risk (OR=5.28; 95\% CI: 3.42-8.15 $\mathrm{I}^{2}=24 \%$; Fig. 4); and increased CRP was associated with a $\sim 4$-fold higher risk (OR=3.99; 95\% CI: 2.61-6.12, $\mathrm{I}^{2}=28 \%$; Fig. 5 and Table III).

Incidence of increased $L D H$ and AST. The meta-analysis also revealed that, compared with patients with moderate COVID-19, the presence of increased AST levels was associated with a $\sim 3$-fold higher risk of severe COVID-19 (OR=3.02; 95\% CI: 2.13-4.26, $\mathrm{I}^{2}=0 \%$; Fig. 6A). Furthermore, the presence of increased LDH levels was associated with an 8 -fold higher risk of severe COVID-19 (OR=8.33; 95\% CI: 1.75-39.69), but this result must be interpreted with caution due to the high heterogeneity $\left(\mathrm{I}^{2}=69 \%\right.$; Fig. 6B and Table III $)$.

\section{Discussion}

SARS-CoV-2, which has a single-strand, positive-sense RNA genome, is a novel Betacoronavirus infecting humans (16). SARS and MERS are also notable exceptions among coronaviruses, as those that are pathogenic to humans are generally associated with mild clinical symptoms (17). Between December 2019 and May 2020, there was a near exponential growth in the number of new cases of SARS-CoV-2 infection, reaching numerous countries globally. The outbreak of COVID-19 has put health authorities worldwide on high alert. At present, all confirmed cases of COVID-19 are diagnosed based on i) clinical manifestations and abnormal findings of chest X-ray or computed tomography and ii) a positive result on the reverse transcription-PCR assay on nasal and pharyngeal swab specimens $(3,15)$. Different clinical characteristics have been reported between patients with moderate and severe COVID-19 (10); however, characteristic differential laboratory abnormalities have yet to be identified. Laboratory diagnostics may contribute to assessing disease severity or predicting prognosis (18). In the present study, laboratory results were collected to investigate the differences that may help distinguish patients with moderate from those with severe COVID-19.

The present meta-analysis revealed that, when compared with patients with moderate disease severity, the presence of leukocytosis, lymphocytopenia, increased PCT and CRP 
Table I. Bias risk assessment.

\begin{tabular}{|c|c|c|c|c|c|c|c|c|c|}
\hline Study (Refs.) & $\begin{array}{c}\text { Clearly } \\
\text { stated } \\
\text { aim }\end{array}$ & $\begin{array}{l}\text { Inclusion of } \\
\text { consecutive } \\
\text { patients }\end{array}$ & $\begin{array}{l}\text { Prospective } \\
\text { collection } \\
\text { of data }\end{array}$ & $\begin{array}{l}\text { Endpoints } \\
\text { appropriate } \\
\text { for study } \\
\text { aim }\end{array}$ & $\begin{array}{l}\text { Unbiased } \\
\text { assessment } \\
\text { of study } \\
\text { endpoint }\end{array}$ & $\begin{array}{l}\text { Follow-up } \\
\text { appropriate } \\
\text { for study } \\
\text { aim }\end{array}$ & $\begin{array}{l}\text { Loss to } \\
\text { follow-up } \\
<5 \%\end{array}$ & $\begin{array}{l}\text { Prospective } \\
\text { calculation } \\
\text { of study } \\
\text { size }\end{array}$ & Score \\
\hline Chen et al (10) & 2 & 2 & 2 & 2 & 2 & 1 & 1 & 0 & 12 \\
\hline Guan et al (11) & 2 & 2 & 2 & 2 & 2 & 0 & 0 & 0 & 10 \\
\hline Huang et al (12) & 2 & 2 & 2 & 2 & 2 & 1 & 2 & 0 & 13 \\
\hline Wang et al (13) & 2 & 2 & 2 & 2 & 2 & 1 & 2 & 0 & 13 \\
\hline Zhang et al (14) & 2 & 2 & 2 & 2 & 2 & 1 & 0 & 0 & 12 \\
\hline Zhang et al (15) & 2 & 2 & 2 & 2 & 2 & 1 & 2 & 0 & 13 \\
\hline
\end{tabular}

Items are scored as 0 (not reported), 1 (reported but inadequate), or 2 (reported and adequate). The global ideal score was 16 for non-comparative studies.

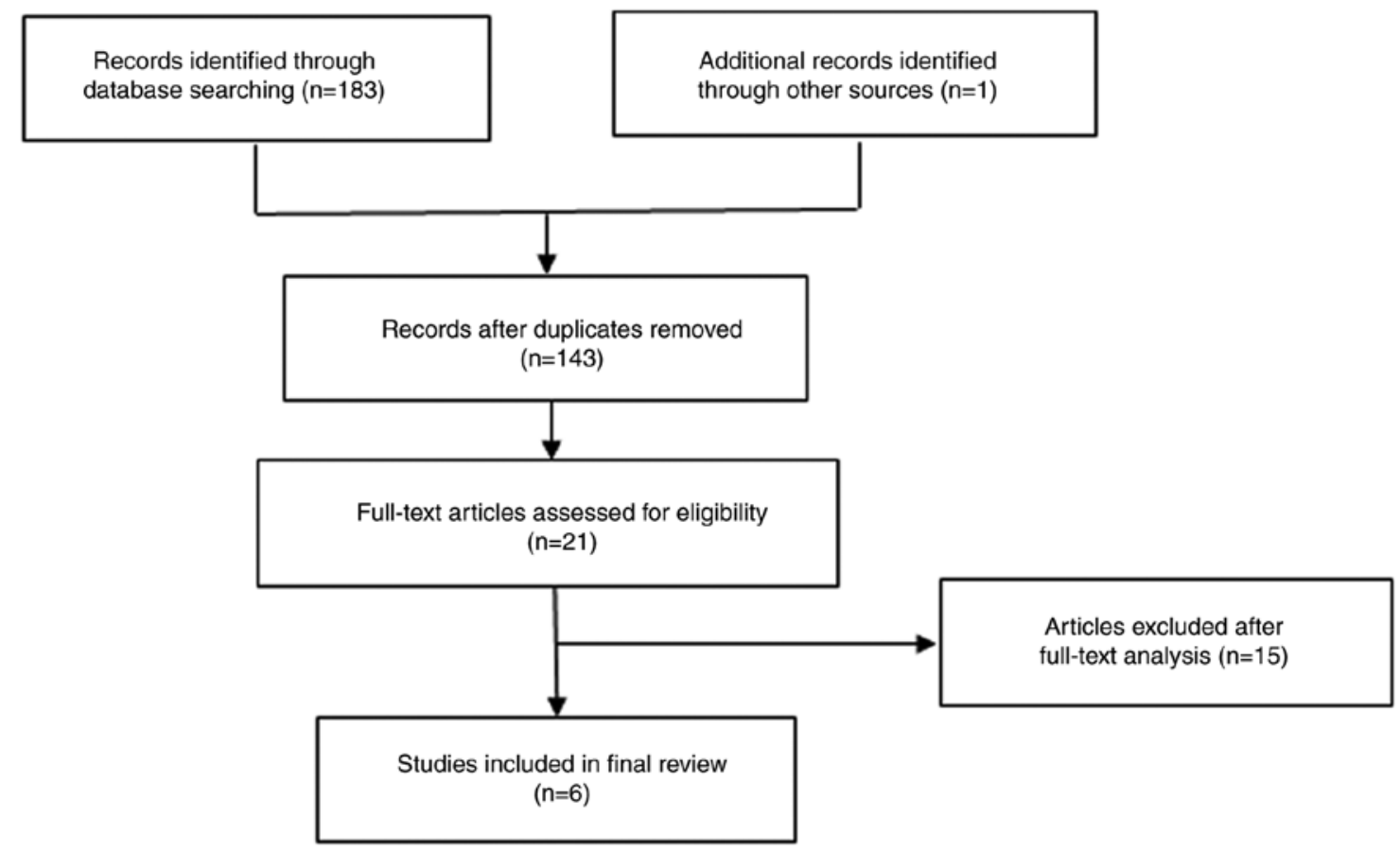

Figure 1. Flowchart of studies eligible for review.

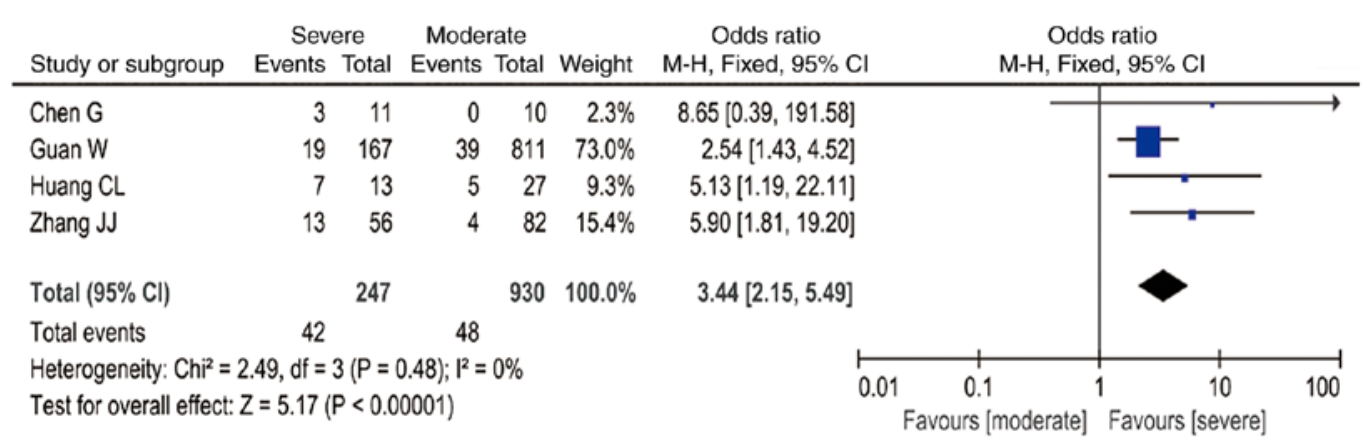

Figure 2. Forest plot of the incidence of leukocytosis.

levels was associated with a 3-, 4-, 5- and 4-fold higher risk of severe COVID-19, respectively. Lippi and Plebani (19) revealed that the white blood cell count, CRP and PCT levels increased, whereas the lymphocyte count decreased 
Table II. Characteristics of the included studies.

\begin{tabular}{|c|c|c|c|c|c|c|}
\hline Study (Refs.) & Country & $\begin{array}{l}\text { No. of patients } \\
\text { (severe/moderate) }\end{array}$ & $\begin{array}{c}\text { Sex } \\
\text { (male/ } \\
\text { female) }\end{array}$ & $\begin{array}{c}\text { Mean } \\
\text { age } \\
\text { (years) }\end{array}$ & Study design & Laboratory results \\
\hline Chen et al (10) & China & $21(11 / 10)$ & $17 / 4$ & 56 & Retrospective & $\begin{array}{l}\text { Leukocytosis, lymphocytopenia, } \\
\text { increased CRP, PCT and LDH }\end{array}$ \\
\hline Guan et al (11) & China & $1099(173 / 926)$ & $637 / 459$ & 47 & Retrospective & $\begin{array}{l}\text { Leukocytosis, lymphocytopenia, } \\
\text { increased CRP, PCT, LDH and AST }\end{array}$ \\
\hline Huang et al (12) & China & $41(13 / 28)$ & $30 / 11$ & 49 & Retrospective & Increased PCT \\
\hline Wang et al (13) & China & $138(36 / 102)$ & $75 / 63$ & 52 & Retrospective & $\begin{array}{l}\text { Leukocytosis, lymphocytopenia, } \\
\text { increased CRP, PCT, LDH and AST }\end{array}$ \\
\hline Zhang et al (14) & China & $140(58 / 82)$ & $71 / 69$ & 57 & Retrospective & $\begin{array}{l}\text { Leukocytosis, lymphocytopenia, } \\
\text { increased CRP and PCT }\end{array}$ \\
\hline Zhang et al (15) & China & $95(32 / 63)$ & $53 / 42$ & 49 & Retrospective & $\begin{array}{l}\text { Leukocytosis, lymphocytopenia, } \\
\text { increased CRP and AST }\end{array}$ \\
\hline
\end{tabular}

CRP, C-reactive protein; PCT, procalcitonin; LDH, lactic dehydrogenase; AST, aspartate aminotransferase.

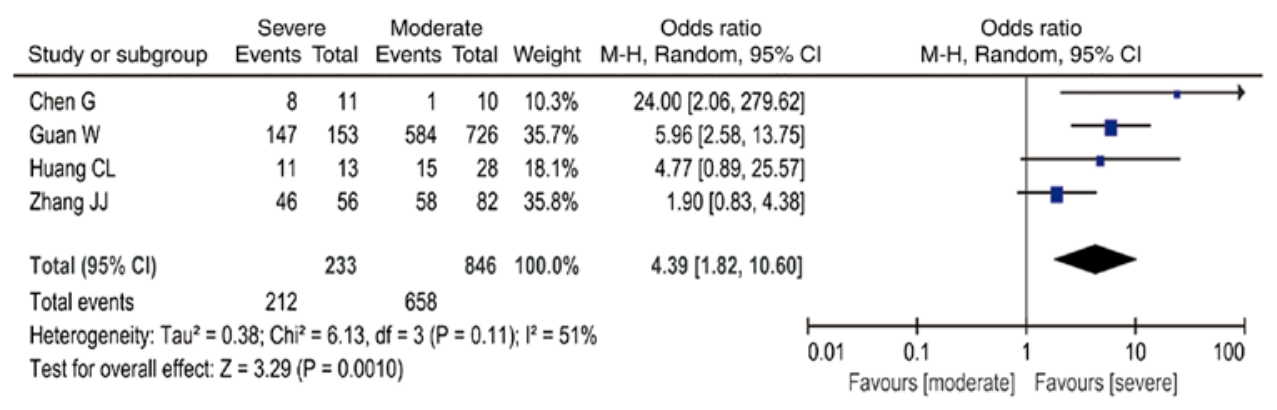

Figure 3. Forest plot of the incidence of lymphocytopenia.

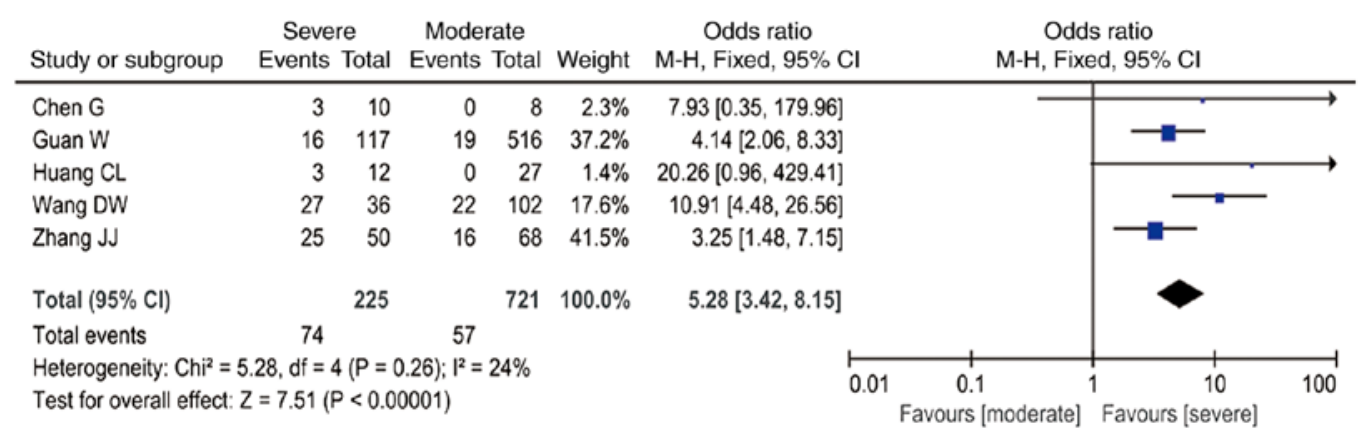

Figure 4. Forest plot of the incidence of increased procalcitonin.

in patients with COVID-19. A further meta-analysis demonstrated that lymphocytopenia and an increase in CRP levels were more common among patients with COVID-19 (6). Rodriguez-Morales et al (20) also reported elevated levels of inflammatory markers, such as CRP and LDH, in patients with COVID-19. The results of the present study demonstrated that the incidence of elevated inflammatory markers also differed between moderate and severe COVID-19 cases. Thus, a higher risk of occurrence of leukocytosis, lymphocytopenia, and increased PCT and CRP levels in this study was correlated with the severity of COVID-19. There remains a question whether the leukocytosis, lymphocytopenia, increased PCT and increased CRP levels are the results or causative factors of the COVID-19 infection, which cannot be determined from our results. These factors may be essential severity criteria, similar to a biomarker, as well as possible targets for intervention to minimize the risk of severe cases.

The mechanisms underlying leukocytosis, lymphocytopenia, and increased PCT and CRP levels in severe cases remain undetermined, but they may be associated with host immune responses during virus infection. Airborne SARS-CoV-2 may enter the peripheral blood from the lungs, leading to infection of 
Table III. Meta-analysis results.

\begin{tabular}{lrr}
\hline Laboratory results & OR, 95\% CI & $\mathrm{I}^{2}$ \\
\hline Leukocytosis & $3.44,2.15-5.49$ & $0 \%$ \\
Lymphocytopenia & $4.39,1.82-10.60$ & $51 \%$ \\
Increased PCT & $5.28,3.42-8.15$ & $24 \%$ \\
Increased CRP & $3.99,2.61-6.12$ & $28 \%$ \\
Increased LDH & $8.33,1.75-39.69$ & $69 \%$ \\
Increased AST & $3.02,2.13-4.26$ & $0 \%$
\end{tabular}

OR, odds ratio; CI, confidence interval; CRP, C-reactive protein; PCT, procalcitonin; LDH, lactic dehydrogenase; AST, aspartate aminotransferase.

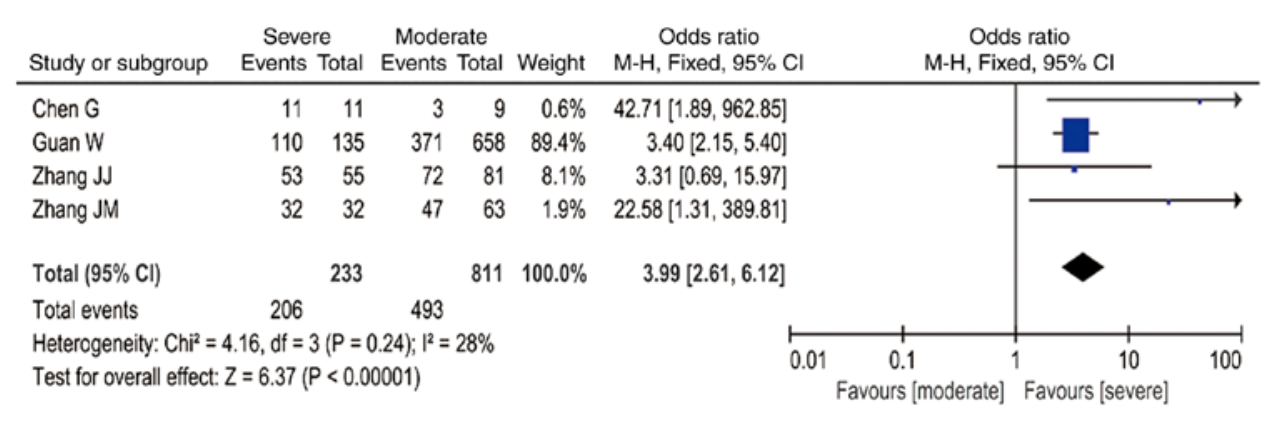

Figure 5. Forest plot of the incidence of increased C-reactive protein.

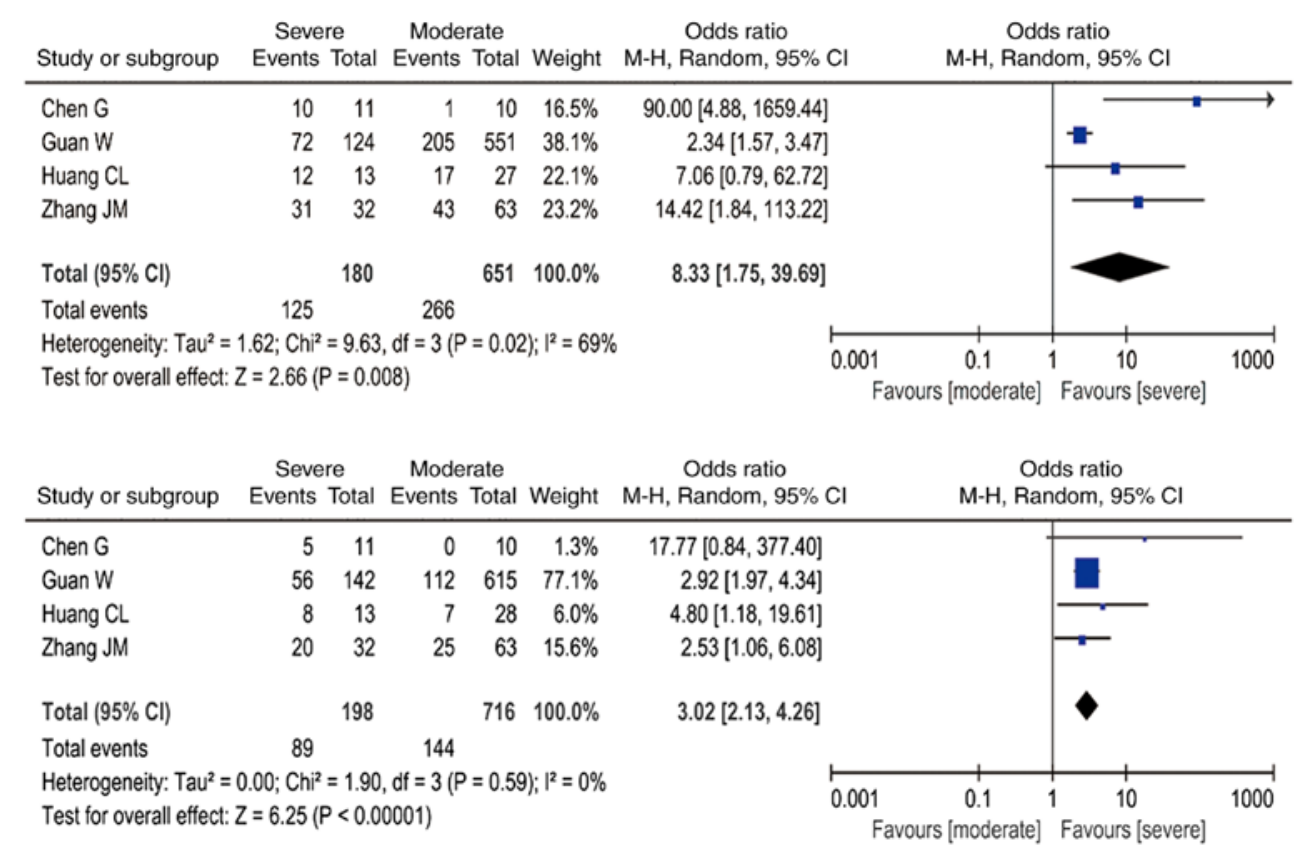

Figure 6. Forest plot of the incidence of increased (A) lactic dehydrogenase and (B) aspartate aminotransferase.

angiotensin-converting enzyme 2-expressing target cells, such as in the lungs, heart, kidneys, gastrointestinal tract, and other unknown target organs (21). Stimulating the innate immune system by pathogen-associated molecular patterns may trigger an antiviral response, leading to activation of several signaling pathways and, ultimately, transcription factors, such as nuclear factor- $\kappa \mathrm{B}$, activator protein 1 , interferon response factor (IRF) 3 and IRF7, accompanied by their nuclear translocation. Simultaneously, the humoral immune response also plays a protective role, as B cells or plasma cells produce specific antibodies to help neutralize viruses, whereas the T-cell responses are aimed at the recognition and killing of infected cells $(22,23)$.

During the host immune responses, the recruitment of neutrophils occurs through chemotaxis of pro-inflammatory 
cytokines, and lymphocyte reduction occurs via different mechanisms, including i) apoptosis or impairment of lymphocytes and ii) bone marrow suppression during a cytokine storm $(22,23)$. Accumulating evidence suggests that the immune system is impaired during the period of disease that allows the development of viral hyperinflammation $(10,24)$. A limited number of studies revealed that severe COVID-19 cases had a relatively distinct profile of decreased memory $\mathrm{T}$ cells and cytotoxic CD8 ${ }^{+} \mathrm{T}$ cells (24). It was also demonstrated that severe COVID-19 may induce a cytokine storm and lymphocyte damage, as well as suppression of interferon- $\gamma$ production (24). The numbers of T cells and B cells were further reduced, while the levels of inflammatory cytokines continued to increase in patients with severe disease (21). Based on the aforementioned results, leukocytosis, lymphocytopenia, and increased PCT and CRP levels may serve as predictive biomarkers for COVID-19 severity.

The results of the present study also demonstrated that, when compared with patients with moderate symptoms, increased LDH and AST levels were more common in patients with severe COVID-19, suggesting that abnormalities in liver function may be present in severe cases; however, Zhang et al (25) did not consider the impairment of liver function to be a prominent characteristic of COVID-19, or to have serious clinical implications. Severe COVID-19 may induce a cytokine storm, and the activated immunity and excessive inflammation are always accompanied by liver tissue injury and liver dysfunction (26); therefore, the liver function of patients with COVID-19 should be carefully monitored, particularly in severe cases.

There were several limitations to the present meta-analysis: i) There were differences in the standards of laboratory results, which depends on the laboratory instruments and testing methods; ii) the number of studies available for inclusion in the sensitivity analysis was limited, resulting in data with considerable heterogeneity that may be inaccurate; and iii) all studies included in the present analysis are retrospective, and the majority of the patients are Chinese. Additional studies of high quality, over a broader geographic scope, should be included to ensure proper clinical intervention.

In conclusion, the incidence of leukocytosis, lymphocytopenia, and elevated CRP, PCT, AST and LDH levels, was increased among patients with severe COVID-19 when compared with patients with moderately severe disease. Serial white blood cell count, lymphocyte count, CRP, PCT, LDH and AST measurements may prove crucial for predicting the progression towards a more severe form of the disease. Inflammatory markers and liver function parameters should be closely monitored in patients with COVID-19, particularly those with severe disease.

\section{Acknowledgements}

Not applicable.

\section{Funding}

The present study was funded by the Ningbo Medical Science and Technology Plan (grant no. 2016A31).

\section{Availability of data and materials}

All data generated or analyzed during this study are included in this published article.

\section{Authors' contributions}

Study design: YH and YZ; data collection: YH, LM and YZ; data analysis and writing of the manuscript: YH, LM and YZ. All the authors have read and approved the final manuscript.

\section{Ethics approval and consent to participate}

Not applicable.

\section{Patient consent for publication}

Not applicable.

\section{Competing interests}

The authors declare that they have no competing interests.

\section{References}

1. WorldHealth Organization. Coronavirus disease 2019(COVID-19): Situation report,73. Available from: https://www.who.int/emergencies/diseases/novel-coronavirus-2019/situation-reports/. Accessed, April 2, 2020.

2. Li Q, Guan X, Wu P, Wang X, Zhou L, Tong Y, Ren R, Leung KSM, Lau EHY, Wong JY, et al: Early transmission dynamics in Wuhan, China, of novel coronavirus-infected pneumonia. N Engl J Med 382: 1199-1207, 2020.

3. The diagnosis and treatment of Coronavirus disease 2019 (version 7). Available from: http://www.cac.gov.cn/.

4. Sun P, Qie S, Liu Z, Ren J, Li K and Xi J: Clinical characteristics of hospitalized patients with SARS-CoV-2 infection: A single arm meta-analysis. J Med Virol 92: 612-617, 2020.

5. Yang J, Zheng Y, Gou X, Pu K, Chen Z, Guo Q, Ji R, Wang H, Wang Y and Zhou Y: Prevalence of comorbidities in the novel Wuhan coronavirus (COVID-19) infection: A systematic review and meta-analysis. Int J Infect Dis 4023: S1201-9712(20)30136-3, 2020.

6. Li LQ, Huang T, Wang YQ, Wang ZP, Liang Y, Huang TB, Zhang HY, Sun WM and Wang YP: 2019 novel coronavirus patients' clinical characteristics, discharge rate, and fatality rate of meta-analysis. J Med Virol: 577-583, 2020.

7. National Health Commission \& State Administration of Traditional Chinese Medicin. Diagnosis and Treatment Protocol for COVID-19 (trial version 7). Updated: 2020-03-29. Available from: http://en.nhc. gov.cn/2020-03/29/c_78469.htm.

8. Farrah K, Young K, Tunis MC and Zhao L: Risk of bias tools in systematic reviews of health interventions: An analysis of PROSPERO-registered protocols. Syst Rev 8: 280, 2019.

9. Slim K, Nini E, Forestier D, Kwiatkowski F, Panis Y and Chipponi J: Methodological index for non-randomized studies (minors): Development and validation of a new instrument. ANZ J Surg 73: 712-716, 2003.

10. Chen G, Wu D, Guo W, Cao Y, Huang D, Wang H, Wang T, Zhang X, Chen $\mathrm{H}$, Yu H, et al: Clinical and immunological features of severe and moderate coronavirus disease 2019. J Clin Invest 130: 2620-2629, 2020.

11. Guan WJ, Ni ZY, Hu Y, Liang WH, Ou CQ, He JX, Liu L, Shan H, Lei CL, Hui DSC, et al: Clinical characteristics of coronavirus disease 2019 in China. N Engl J Med 382: 1708-1720, 2020.

12. Huang C, Wang Y, Li X, Ren L, Zhao J, Hu Y, Zhang L, Fan G, $\mathrm{Xu}$ J, Gu X, et al: Clinical features of patients infected with 2019 novel coronavirus in Wuhan, China. Lancet 395: 497-506, 2020.

13. Wang D, Hu B, Hu C, Zhu F, Liu X, Zhang J, Wang B, Xiang H, Cheng Z, Xiong Y, et al: Clinical characteristics of 138 hospitalized patients with 2019 novel coronavirus-infected pneumonia in Wuhan, China. JAMA 323: 1061-1069, 2020. 
14. Zhang JJ, Dong X, Cao YY, Yuan YD, Yang YB, Yan YQ, Akdis CA and Gao YD: Clinical characteristics of 140 patients infected with SARS-CoV-2 in Wuhan, China. Allergy 75: $1730-1741,2020$

15. Zhang G, Zhang J, Wang B, Zhu X, Wang Q and Qiu S: Analysis of clinical characteristics and laboratory findings of 95 cases of 2019 novel coronavirus pneumonia in Wuhan, China: A retrospective analysis. Respir Res 21: 74, 2020.

16. Lu R, Zhao X, Li J, Niu P, Yang B, Wu H, Wang W, Song H, Huang B, Zhu N, et al: Genomic characterisation and epidemiology of 2019 novel coronavirus: Implications for virus origins and receptor binding. Lancet 395: 565-574, 2020.

17. Su S, Wong G, Shi W, Liu J, Lai ACK, Zhou J, Liu W, Bi Y and Gao GF: Epidemiology, genetic recombination, and pathogenesis of coronaviruses. Trends Microbiol 24: 490-502, 2016.

18. Lippi $\mathrm{G}$ and Plebani M: A modern and pragmatic defnition of laboratory medicine. Clin Chem Lab Med 58: 1171, 2020.

19. Lippi $\mathrm{G}$ and Plebani M: Laboratory abnormalities in patients with COVID-2019 infection. Clin Chem Lab Med 58: 1131-1134, 2020.

20. Rodriguez-Morales AJ,Cardona-Ospina JA, Gutiérrez-Ocampo E, Villamizar-Peña R, Holguin-Rivera Y, Escalera-Antezana JP, Alvarado-Arnez LE, Bonilla-Aldana DK, Franco-Paredes C, Henao-Martinez AF, et al: Clinical, laboratory and imaging features of COVID-19: A systematic review and meta-analysis. Travel Med Infect Dis 34: 101623, 2020.

21. Lin L, Lu L, Cao W and Li T: Hypothesis for potential pathogenesis of SARS-CoV-2 infection-a review of immune changes in patients with viral pneumonia. Emerg Microbes Infect 9: $727-732,2020$.
22. Rokni M, Ghasemi V and Tavakoli Z: Immune responses and pathogenesis of SARS-CoV-2 during an outbreak in Iran: Comparison with SARS and MERS. Rev Med Virol 30: e2107, 2020.

23. Azkur AK, Akdis M, Azkur D, Sokolowska M, van de Veen W, Brüggen MC, O'Mahony L, Gao Y, Nadeau K and Akdis CA: Immune response to SARS-CoV-2 and mechanisms of immunopathological changes in COVID-19. Allergy 75: 1564-1581, 2020.

24. Qin C, Zhou L, Hu Z, Zhang S, Yang S, Tao Y, Xie C, Ma K, Shang K, Wang W and Tian DS: Dysregulation of immune response in patients with coronavirus 2019 (COVID-19) in Wuhan, China. Clin Infect Dis 71: 762-768, 2020.

25. Zhang Y, Zheng L, Liu L, Zhao M, Xiao J and Zhao Q: Liver impairment in COVID-19 patients: A retrospective analysis of 115 cases from a single centre in Wuhan city, China. Liver Int 40: 2095-2103, 2020.

26. Possamai LA, Thursz MR, Wendon JA and Antoniades CG: Modulation of monocyte/macrophage function: A therapeutic strategy in the treatment of acute liver failure. J Hepatol 61: 439-445, 2014

c) () $($ ) This work is licensed under a Creative Commons cc. At No No Atribution-NonCommercial-NoDerivatives 4.0 International (CC BY-NC-ND 4.0) License. 